\title{
SI
}

\section{Detecting Framework Distortions predicted by Hybrid-DFT: An Opportunity to improve the M1 Catalyst.}

Douglas A. Blom ${ }^{1}$ and Thomas Vogt ${ }^{\star 2}$

${ }^{1}$ Department of Chemical Engineering \& NanoCenter, University of South Carolina Columbia, SC 29208, USA, blomd@mailbox.sc.edu

2 Department of Chemical Engineering, Chemistry and Biochemistry \& NanoCenter, University of South Carolina Columbia, SC 29208, USA,

Corresponding author Thomas Vogt email: tvogt@mailbox.sc.edu

Acknowledgment: DAB and TV are supported by U.S. ARO Contract \# W911NF-20-1-0318. 
Figure S1:

Particle 1

HAADF

Image 
Figure S2

Particle 2

HAADF

Image

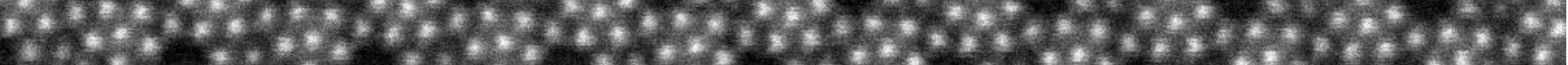

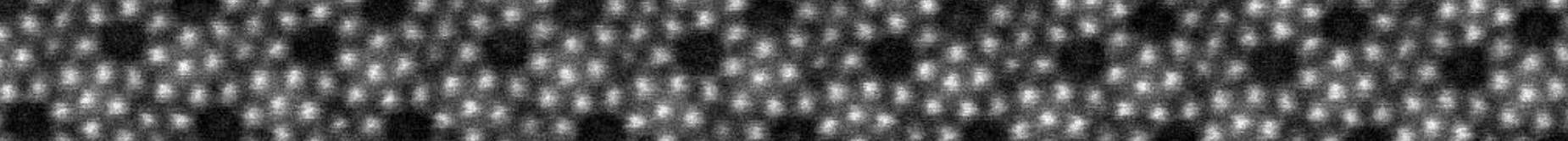

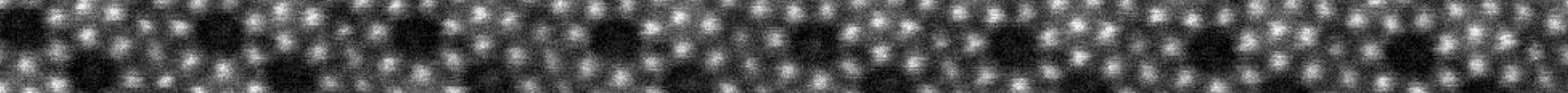

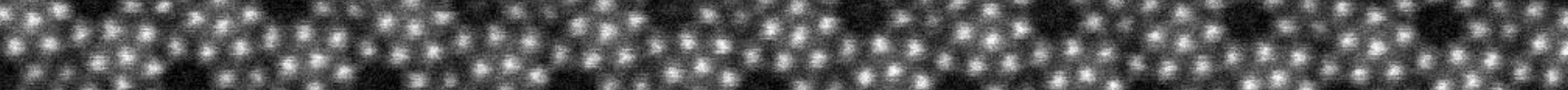

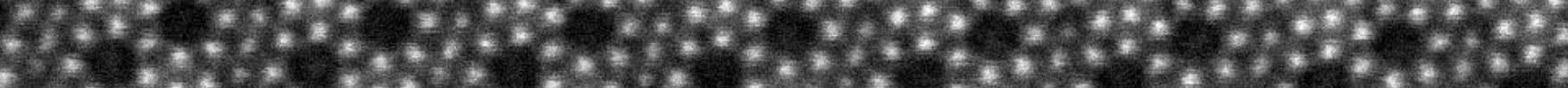

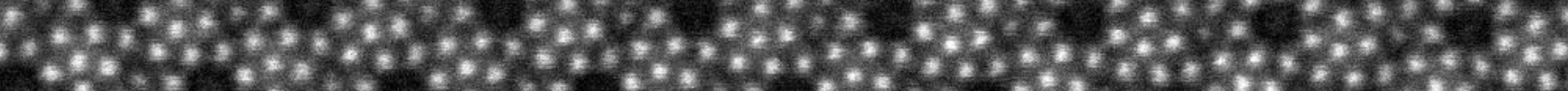

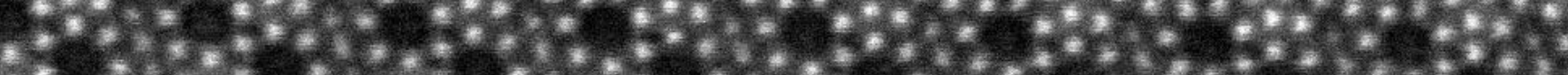



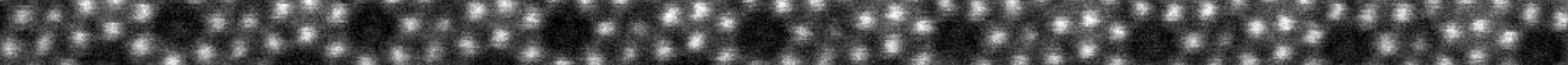

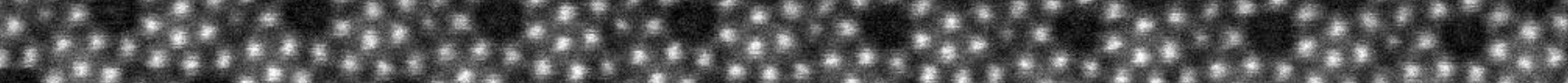

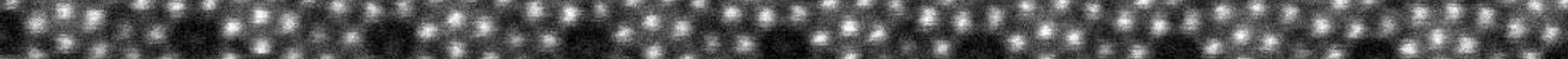

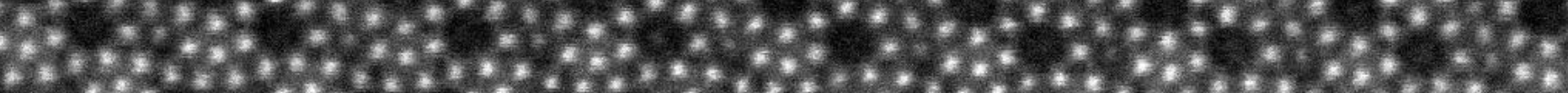

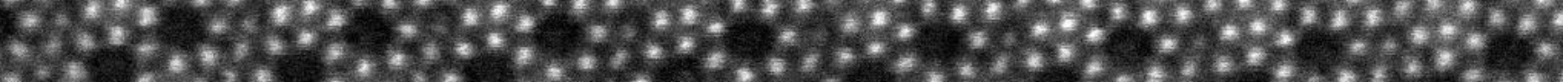

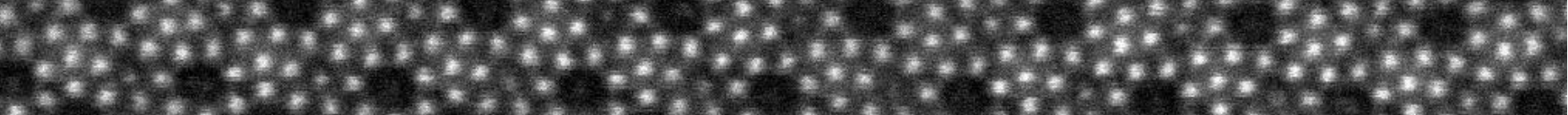

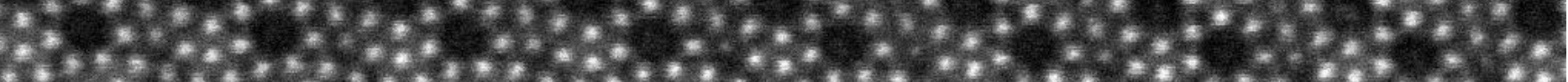

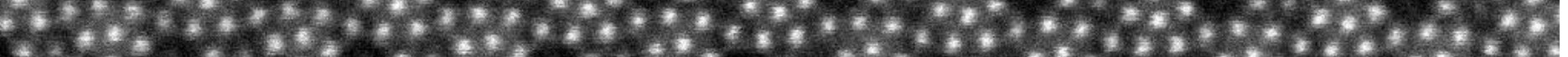

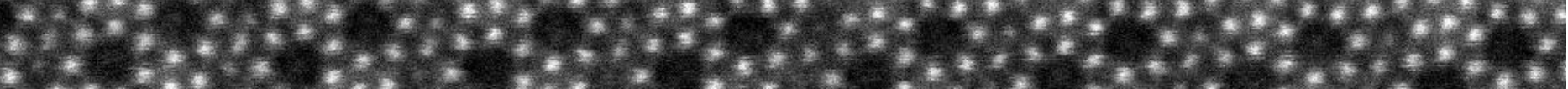

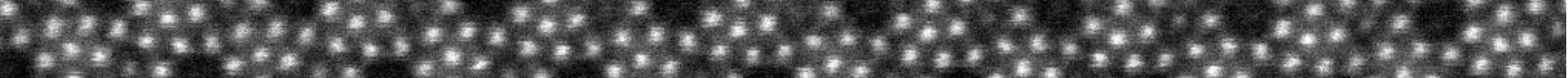

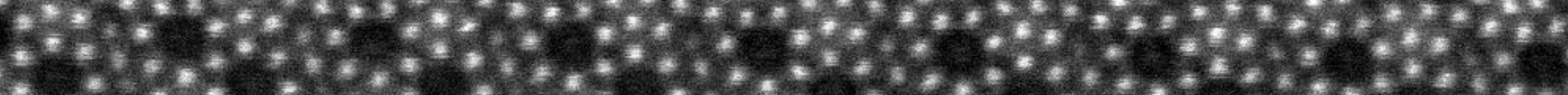

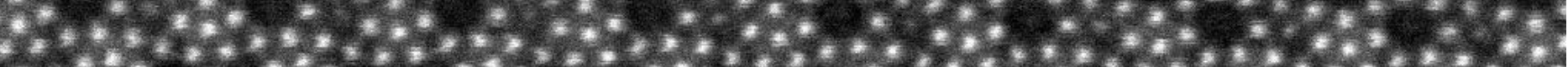

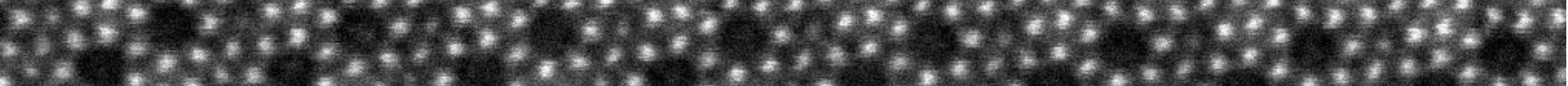

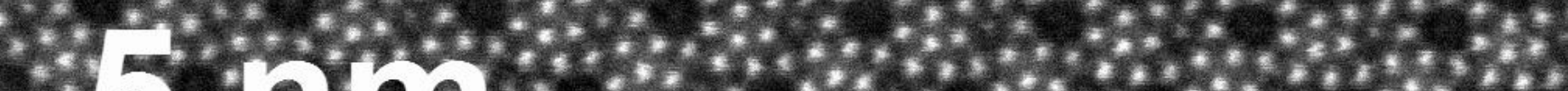

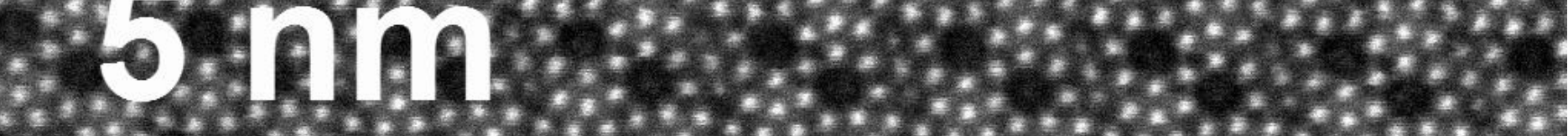

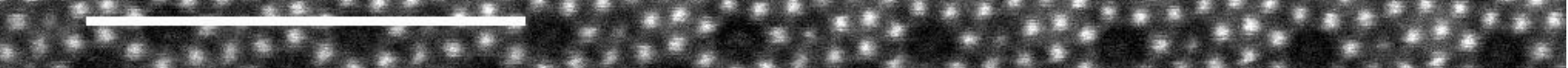


Figure S3:

Particle 3

HAADF

Image

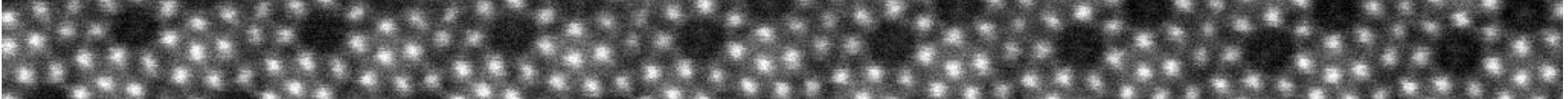

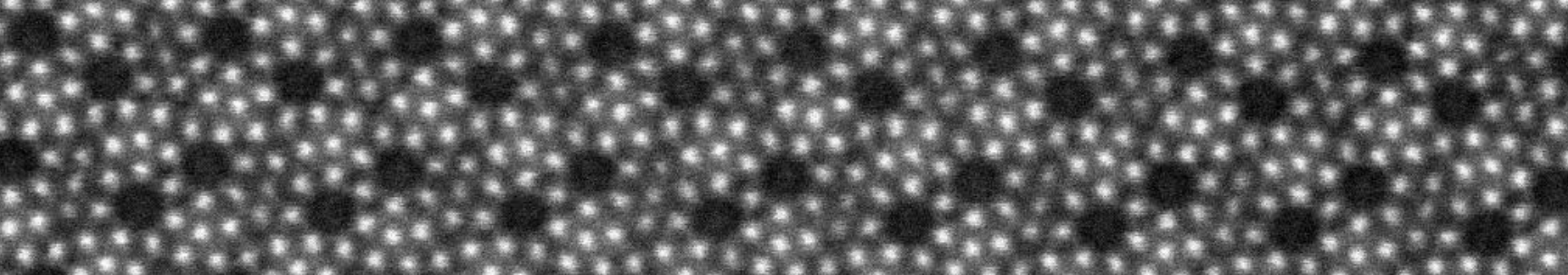

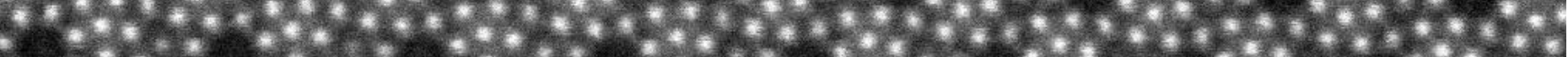

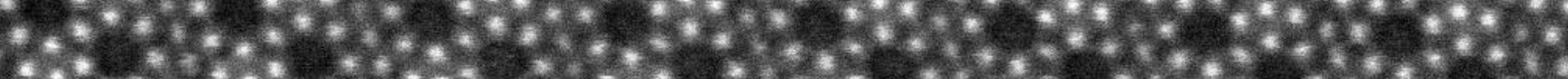

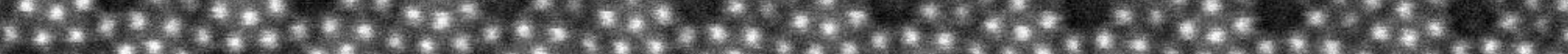

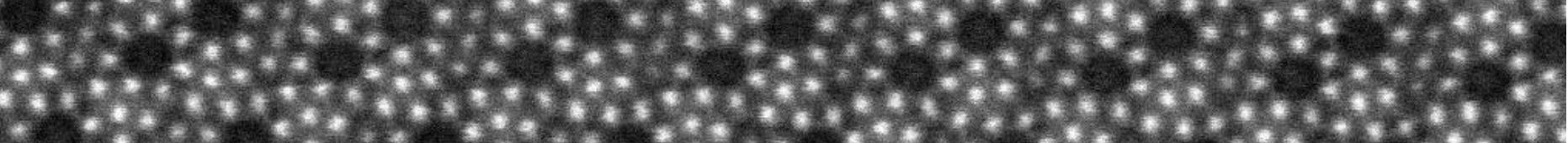

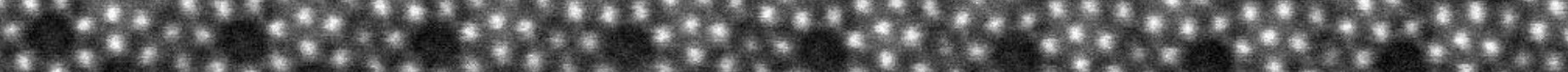

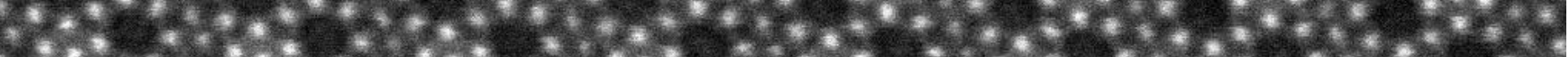

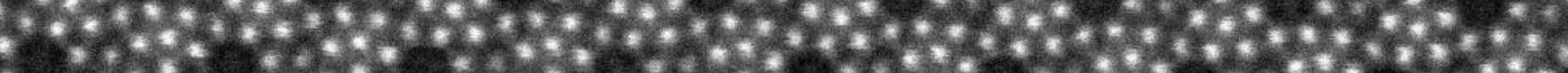

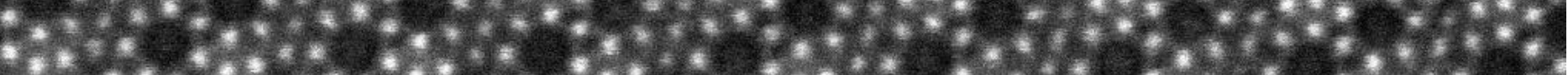

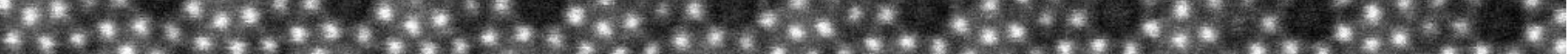

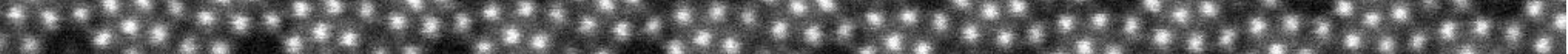

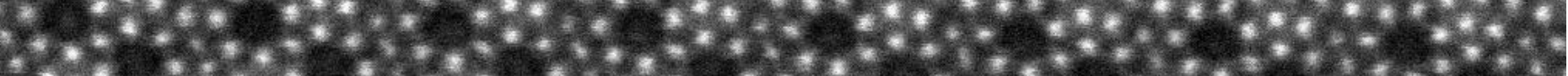

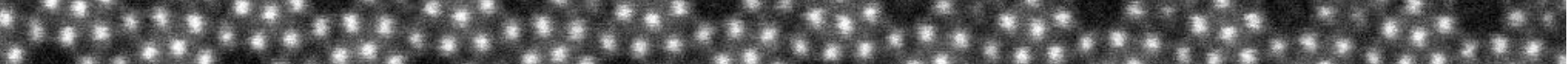

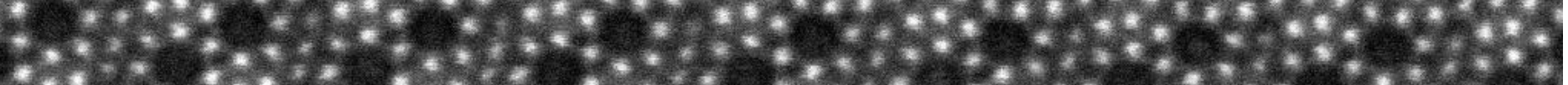

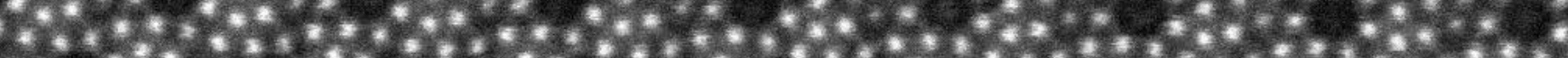



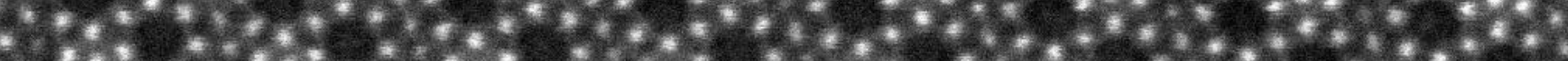

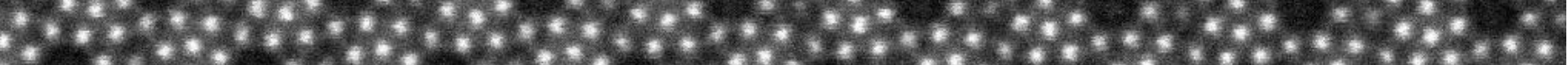

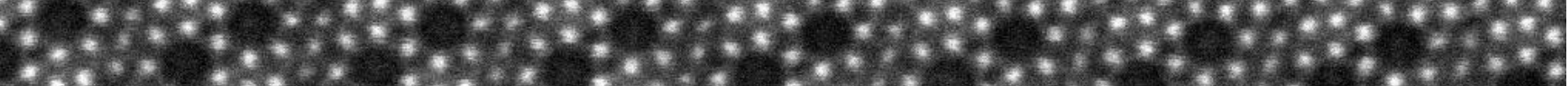

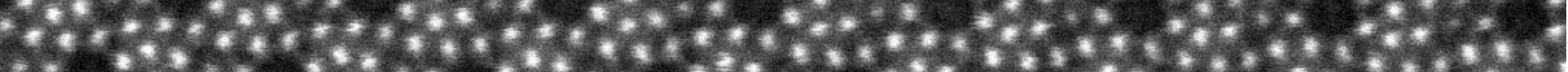

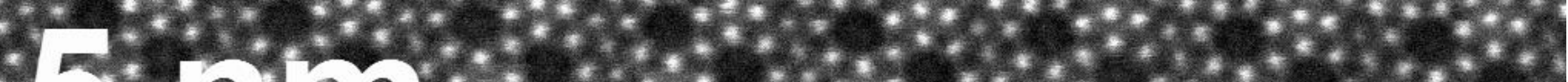

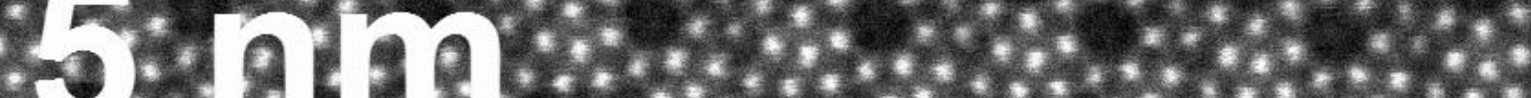

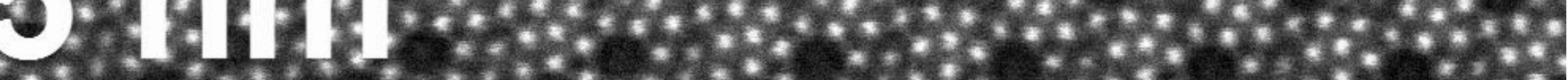
20 


\section{Figure S4: \\ Particle 4 \\ Bright Field Image}

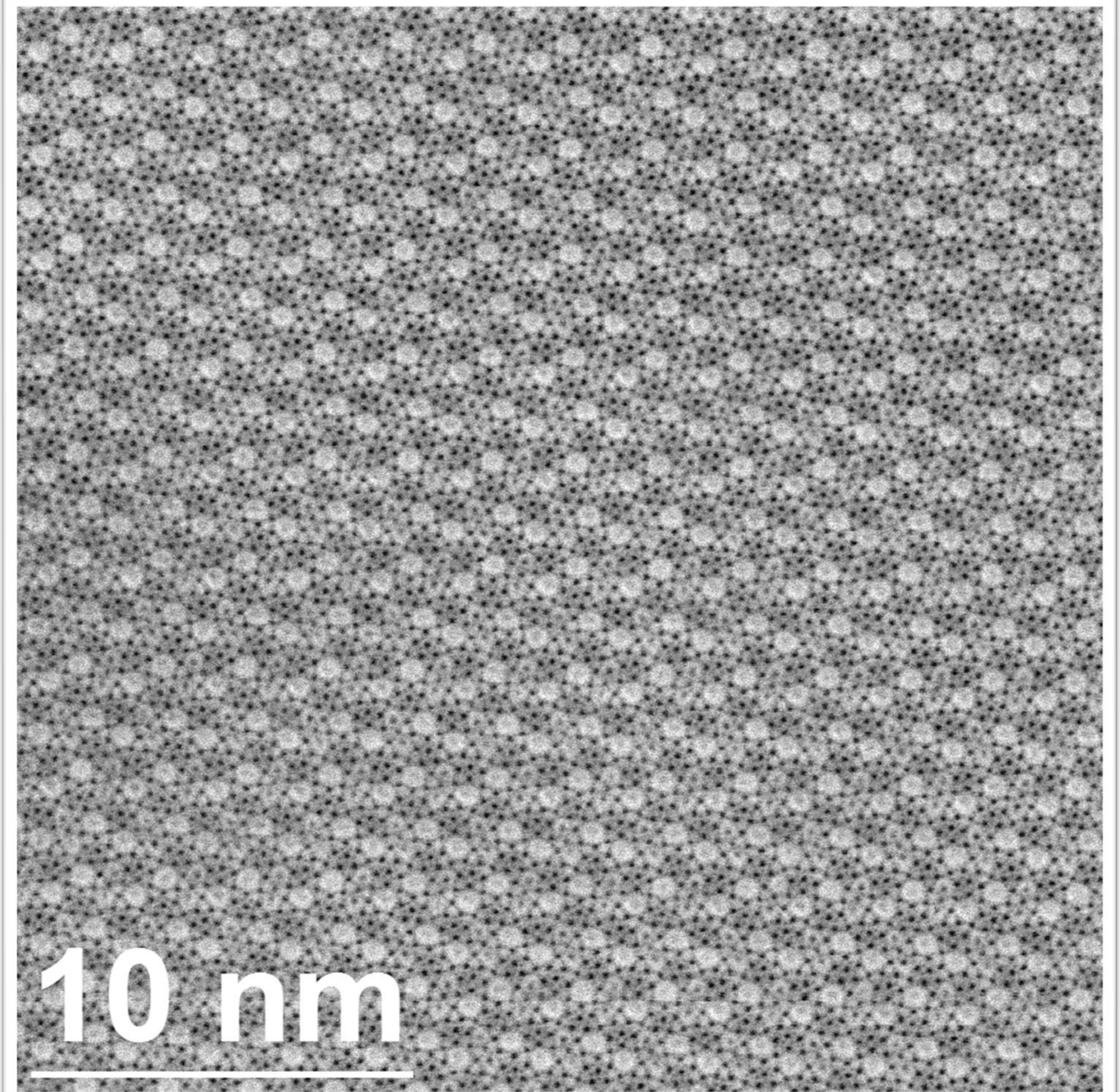

